\title{
Structural brain alterations associated with dyslexia predate reading onset
}

\section{Citation}

Raschle, Nora Maria, Maria Chang, and Nadine Gaab. 2011. “Structural Brain Alterations Associated with Dyslexia Predate Reading Onset." Neurolmage 57 (3) (August): 742-749. doi:10.1016/j.neuroimage.2010.09.055.

\section{Published Version}

doi:10.1016/j.neuroimage.2010.09.055

\section{Permanent link}

http://nrs.harvard.edu/urn-3:HUL.InstRepos:30085111

\section{Terms of Use}

This article was downloaded from Harvard University's DASH repository, and is made available under the terms and conditions applicable to Other Posted Material, as set forth at http:// nrs.harvard.edu/urn-3:HUL.InstRepos:dash.current.terms-of-use\#LAA

\section{Share Your Story}

The Harvard community has made this article openly available.

Please share how this access benefits you. Submit a story.

\section{Accessibility}




\title{
Structural brain alterations associated with dyslexia predate reading onset
}

\author{
Nora Maria Raschle, Maria Chang, and Nadine Gaab* \\ Children's Hospital Boston, Department of Medicine, Division of Developmental Medicine, \\ Laboratories of Cognitive Neuroscience, 1 Autumn Street, Mailbox \# 713, Boston, MA 02115, \\ USA
}

\begin{abstract}
Functional magnetic resonance imaging studies have reported reduced activation in parietotemporal and occipitotemporal areas in adults and children with developmental dyslexia compared to controls during reading and reading related tasks. These patterns of regionally reduced activation have been linked to behavioral impairments of reading-related processes (e.g., phonological skills and rapid automatized naming). The observed functional and behavioral differences in individuals with developmental dyslexia have been complemented by reports of reduced gray matter in left parietotemporal, occipitotemporal areas, fusiform and lingual gyrus and the cerebellum. An important question for education is whether these neural differences are present before reading is taught. Developmental dyslexia can only be diagnosed after formal reading education starts. However, here we investigate whether the previously detected gray matter alterations in adults and children with developmental dyslexia can already be observed in a small group of pre-reading children with a family-history of developmental dyslexia compared to age and IQ-matched children without a family-history $(N=20 /$ mean age: 5:9 years; age range 5:1-6:5 years). Voxel-based morphometry revealed significantly reduced gray matter volume indices for pre-reading children with, compared to children without, a family-history of developmental dyslexia in left occipitotemporal, bilateral parietotemporal regions, left fusiform gyrus and right lingual gyrus. Gray matter volume indices in left hemispheric occipitotemporal and parietotemporal regions of interest also correlated positively with rapid automatized naming. No differences between the two groups were observed in frontal and cerebellar regions. This discovery in a small group of children suggests that previously described functional and structural alterations in developmental dyslexia may not be due to experience-dependent brain changes but may be present at birth or develop in early childhood prior to reading onset. Further studies using larger sample sizes and longitudinal analyses are needed in order to determine whether the identified structural alterations may be utilized as structural markers for the early identification of children at risk, which may prevent the negative clinical, social and psychological outcome of developmental dyslexia.
\end{abstract}

\section{Keywords}

fMRI; Children; Dyslexia; Voxel-based morphometry; Reading; Family history

\footnotetext{
(C) 2010 Elsevier Inc. All rights reserved.

* Corresponding author. Harvard Medical School, Children's Hospital Boston, Department of Medicine, Division of Developmental Medicine, Laboratories of Cognitive Neuroscience, 1 Autumn Street, Boston, MA 02115, USA. Fax: +16177300518. nadine.gaab@childrens.harvard.edu (N.Gaab)..

Supplementary materials related to this article can be found online at doi:10.1016/j.neuroimage.2010.09.055.
} 


\section{Introduction}

Developmental dyslexia, which affects 5-17\% of all children, is a specific learning disability characterized by difficulties with accurate and/or fluent word recognition, poor spelling and decoding skills (Beitchman et al., 1986). Difficulties in reading are disproportionate to other cognitive abilities (such as IQ) and cannot be explained by poor vision, hearing difficulty or a lack of motivation or educational opportunities (World Health Organization, 1992). Familial occurrences and twin studies suggest that developmental dyslexia is highly heritable, occurring in up to $40 \%$ of individuals who have a first-degree relative with developmental dyslexia (Fisher and Francks, 2006; Smith et al., 1983). Several candidate susceptibility genes for developmental dyslexia have been reported (Galaburda et al., 2006). The majority of these genes are shown to be important for brain development and it has been suggested that developmental dyslexia may be caused by abnormal migration and/or maturation of neurons during early development (Galaburda et al., 2006). Currently, developmental dyslexia can only be diagnosed after the onset of formal reading instruction (around second or third grade in the United States). However, identifying a child after reading onset limits the time available for early interventions that may prevent the serious clinical, psychological and social impact of developmental dyslexia. Educational neuroscience offers methods for identifying early biomarkers of educational risk, for example via structural differences in the dyslexic brain that pre-date being taught to read.

To date, studies focusing on the early detection of children at risk for developmental dyslexia have mainly centered on behavioral correlates of reading abilities. These studies suggest that linguistic impairments such as deficits in language comprehension, phonological processing or impaired letter name knowledge prior to formal reading instruction predict reading ability in children with and without a family history of developmental dyslexia (e.g.; Flax et al., 2008; Gallagher et al., 2000; Pennington and Lefly, 2001; Puolakanaho et al., 2008; Scarborough, 1990; Snowling et al., 2003). Additionally, several studies have found deficits in rapid automatized naming prior to formal reading instruction which predict later reading abilities (De Jong and Van der Leij, 1999; Kirby et al., 2003; Kobayashi et al., 2005; Wolf, 1986; Wolf et al., 1986). Furthermore, research suggests that both phonological processing and rapid automatized naming contribute uniquely and substantially to word reading from grade 1 to grade 6 (Vaessen and Blomert, 2010). However, the feasibility of these behavioral correlates as effective screening measures remains a challenge (Gabrieli, 2009).

Several studies have utilized brain measures to study young children at risk for developmental dyslexia and healthy controls. Electrophysiological differences have been reported for infants with familial risk for developmental dyslexia for basic auditory and language processing (e.g.; Guttorm et al., 2001, 2003; Pihko et al., 1999; Leppanen et al., 2002). However, to date only one study has reported neural predictors of reading abilities (Maurer et al., 2009) in children with and without a familial risk of dyslexia. In a 5-year longitudinal study, neurophysiological and behavioral measures obtained in 6 year old kindergarteners with and without a family history of dyslexia predicted reading outcome after reading instruction. Neurophysiological measures in kindergarten furthermore improved reading prediction in comparison to behavioral measures alone and were the only predictor for reading success in fifth grade.

Previous neuroimaging studies revealed differences in brain structure and function between school-age children and adults with a diagnosis of developmental dyslexia and controls. Using functional magnetic resonance imaging (fMRI), individuals with developmental dyslexia showed reduced activation during reading and reading related tasks in left- 
hemispheric occipitotemporal regions which correlated with reduced reading skills (Hoeft et al., 2007b; Temple, 2002; Specht et al., 2009).

Structural magnetic resonance imaging (MRI) with voxel-based morphometry (VBM) revealed decreased gray matter volume indices in individuals with developmental dyslexia, when compared to typical reading controls, in several brain regions, such as left occipitotemporal and temporoparietal areas (Brambati et al., 2004; Brown et al., 2001; Eckert et al., 2005; Hoeft et al., 2007a; Kronbichler et al., 2008; Pernet et al., 2009; Silani et al., 2005), bilateral fusiform (Kronbichler et al., 2008) and lingual gyrus (Eckert et al., 2005) as well as the cerebellum (Brambati et al., 2004; Brown et al., 2001; Eckert et al., 2005). Moreover, gray matter volume indices in these areas were positively correlated with prereading and reading skills, such as timed and untimed (pseudo-)word reading (Kronbichler et al., 2008; Pernet et al., 2009; Silani et al., 2005; Steinbrink et al., 2008), phonological processing (Kronbichler et al., 2008; Pernet et al., 2009), spelling performance (Pernet et al., 2009) and rapid automatized naming (RAN) (Kronbichler et al., 2008). Similarly, white matter organization, as characterized by diffusion tensor imaging (DTI), is found to be weaker in left posterior brain regions in individuals with developmental dyslexia and correlate positively with reading skills, such as reading speed or word and pseudo-word reading (Klingberg et al., 2000; Silani et al., 2005; Steinbrink et al., 2008).

It remains unclear whether these morphological differences exist at birth, develop during the first few years of life, or are due to experience-dependent structural changes that occur after the onset of formal reading education. In the current study we utilized VBM (Ashburner and Friston, 2005) to investigate whether the previously reported differences in gray matter volume indices in individuals with developmental dyslexia can already be observed in a small group of five year old pre-readers with a family-history of developmental dyslexia.

Our focus on an understudied age group (pre-reader to beginning readers) within the dyslexia population is highly significant, as it provides an opportunity to examine potential predictors for an age group for which intervention might be most efficacious. For example, it has been shown that children with learning disabilities are less likely than their peers to enroll in programs of higher education (Wagner, 1993) or complete high school (Marder, 1992) and are more likely to enter the juvenile justice system (Quinn et al., 2001). Early identification of predictors of reading disability in pre-reading children offers a chance to eliminate these significant personal and social costs. A modified approach to the way we teach children how to read must include early identification and the development of early preventive strategies. The identification of a child with reading disabilities in midelementary school may be too late. By this stage, the delayed development of reading has already affected children's vocabulary skills (Cunningham and Stanovich, 1991) and motivation to read (Oka and Paris, 1986), thus leading to missed opportunities for the development of comprehension strategies (Brown et al., 1986). Studies have shown that children who are weak readers at the end of first grade remain poor readers by the end of elementary school (Francis and Shaywitz, 1996; Torgesen and Buress, 1998). Improved early identification of children at risk (behavioral or family risk) using neural pre-markers may further lead to changes in educational policies and will make it possible to assign independent educational plans and customized curriculums for children at risk prior to formal schooling.

\section{Methods}

\section{Subjects}

Twenty healthy, native English speaking children with (FHD+/n=10) and without (FHD-/ $n=10$ ) a family-history of developmental dyslexia, have been included in the present 
analyses. All children are enrolled in our larger longitudinal study which also employs functional imaging, psychophysical measures as well as conducts genetic testing. FHD+ children (mean age 5 years and 11 months) had at least one first degree relative with a clinical diagnosis of developmental dyslexia. Children with a family-history of reading difficulties, but no clinical diagnosis of developmental dyslexia in the family were excluded from the study. FHD- children (mean age 5 years and 7 months) had no first degree relatives with developmental dyslexia and no self-reported history of reading difficulties or language delays in their families. Children were screened for hearing and vision difficulties, neurological disease or psychiatric disorders through a parent questionnaire. The two groups of FHD+ and FHD-children were matched by group for age, gender and non-verbal IQ (Kaufman Brief Intelligence Test, 2nd edition; Kaufman and Kaufman, 1997). Data obtained in the national early childhood longitudinal study (ECLS-K, kindergarten class of 19981999 ) indicate that by kindergarten entry only $2 \%$ of all children are able to identify sight words and no more than $1 \%$ recognize words in context (Denton et al., 2000). Based on this study, only pre-reading children were enrolled in our study. During an initial telephone/ email-screening with the parents, we screened for pre-reading status in all children. Only pre-reading children (parent report) planning to receive formal reading instruction within the next months were invited to take part in the study. Furthermore, the Word Identification subtest of the Woodcock Reading Mastery Test (WRMT; Woodcock, 1998) was administered to assure pre-reading status. For the Word Identification subtest the child is required to identify isolated words presented in the test booklet. For an answer to be scored as correct, the child must produce a natural or fluent reading of the word within about five seconds. Seventeen children (9 FHD+/8 FHD-) were not able to read a single word, two children (1 FHD+/1 FHD-) recognized two and one child (FHD+) recognized seven isolated words. All children were tested between May and November of their kindergarten entry year (based on the reading curriculum, children should be able to read first words by the end of November of their kindergarten year). This study was approved by the ethics committee of Children's Hospital Boston. Verbal assent and informed consent was obtained from each child and guardian, respectively.

\section{Behavioral group characteristics}

Participants were characterized by a test battery of standardized assessments examining language and pre-reading skills, such as expressive and receptive vocabulary (Clinical Evaluation of Language Fundamentals (CELF Preschool 2nd edition); Semel et al., 1986), phonological processing (Comprehensive Test of Phonological Processing (CTOPP); Wagner et al., 1999) and RAN (Rapid Automatized Naming Test; Wolf and Denckla, 2005). Additionally, potential confounds included socioeconomic status and home literacy environment. All participating families were given a socioeconomic background questionnaire (questions adapted from the MacArthur Research Network: http:// www.macses.ucsf.edu/Default.htm) and answered questions concerning the home literacy environment (based on Denney et al., 2001 as cited in Katzir et al., 2009). For a complete overview of SES and HLE questions see SI1 and SI2).

\section{Imaging procedure}

For all participants an age-appropriate neuroimaging protocol was used, which included an intensive familiarization with the MRI equipment in a mock scanner area prior to the actual neuroimaging session (Raschle et al., 2009). T1-weighted MPRAGE MRI sequences were acquired on a Siemens $3 \mathrm{~T}$ whole body scanner with the following specifications: 128 slices, TR $2000 \mathrm{~ms}$; TE $3.39 \mathrm{~ms}$; flip angle $9^{\circ}$; field of view $256 \mathrm{~mm}$; voxel size $1.3 \times 1.0 \times 1.3 \mathrm{~mm}$. Whole brain structural brain images were collected for all children between August and November prior to their or within the first few weeks of their first kindergarten year. 


\section{VBM analysis and statistics}

We utilized optimized voxel-based morphometry (Ashburner and Friston, 2005), a wholebrain analysis technique, to examine differences in gray matter volume indices between prereading FHD+ and FHD- children. In particular, the VBM5.1 toolbox (http:// www.dbm.neuro.uni-jena.de/vbm) was employed using SPM5 software (http:// www.fil.ion.ucl.ac.uk/spm) executed in MATLAB (Mathworks, Natick, MA). All images were segmented, bias-corrected and spatially normalized to a customized pediatric brain template specific to the group's characteristics (e.g. age and gender) to account for brain size and development within our pediatric population (mean: 5 years and 9 months). The template was generated using Template-O-Matic, a toolbox to create customized brain templates of high quality, especially in smaller subject samples (Wilke et al., 2008). Using unified segmentation, the images were segmented into gray matter, white matter and cerebrospinal fluid. Data quality was assured with a sample homogeneity test by plotting the standard deviation of the normalized, gray matter segmented brain volumes across all subjects. The covariance between each gray matter volume is hereby visualized using a boxplot and covariance matrices (for VBM manual and details see http:// www.dbm.neuro.uni-jena.de/vbm). Finally, bias-corrected, whole brain Jacobian modulated images (preserving total gray matter volume) were smoothed with a 12-mm full width at half maximum isotropic Gaussian kernel (Ashburner and Friston, 2005).

Regional variations in gray matter volume indices (GMVI, corresponding to the percentage of gray matter in a given voxel) between FHD+ and FHD- children were calculated using a two-sample $t$-test. Statistical significance thresholds were applied at the voxel-level ( $p<0.001$, uncorrected). Results for the whole brain analysis were obtained using nonstationary correction ( $p<0.01$ cluster size extent value), which is essential to adjust cluster sizes according to local roughness (Hayasaka et al., 2004). To examine the relationship between structural and behavioral measures, we defined two main regions of interests. The ROIs were defined by an $8 \mathrm{~mm}$ radius sphere, centered around parietotemporal and occipitotemporal activation peaks as identified in a meta-analysis of 35 neuroimaging studies of word and pseudoword reading (Jobard et al., 2003). They further overlap with the observed anatomical differences between pre-reading children with and without a familyhistory of developmental dyslexia in the current study. Using the brain imaging toolbox (BIT, Gabrieli Lab, Department of Brain and Cognitive Sciences, Massachusetts Institute of Technology, Cambridge, MA, USA) a parietotemporal ROI was created at $x=-44 \pm 4 ; y=-$ $58 \pm 5 ; z=-15 \pm 6$ and a more occipitotemporal ROI at $x=-60 \pm 4 ; y=-41 \pm 6 ; z=25 \pm 6$. The two ROIs were normalized to our customized pediatric template, which accounts for brain size and development within our pediatric population. Next, mean GMVIs of these ROIs were extracted for each individual. Finally, the average of GMVIs within each ROI for the whole experimental group ( $n=20 ; 10$ FHD+/10 FHD-) was correlated with standardized behavioral measures, which have shown to predict reading ability: phonological processing (e.g. Flax et al., 2008; Gallagher et al., 2000; Pennington and Lefly, 2001; Puolakanaho et al., 2008; Scarborough, 1990; Snowling et al., 2003;) and RAN (De Jong and Van der Leij, 1999; Kirby et al., 2003; Kobayashi et al., 2005; Wolf, 1986; Wolf et al., 1986). Statistical correlation analysis was performed using SPSS software package, version 16.0 (SPSS Inc., 1999). Significance thresholds of this ROI correlation analysis were corrected for multiple comparisons by controlling for the false discovery rate (FDR, Benjamini and Hochberg, 1995). 


\section{Results}

\section{Demographics and behavioral data}

Demographic characteristics of all participants are listed in Table 1. We observed significant differences in standardized behavioral assessments of RAN between children with a family history of developmental dyslexia (FHD+) compared to children without a family-history of developmental dyslexia (FHD-) ( $p \unlhd(001$; Table 1). Mean scores of expressive and receptive language skills and phonological processing appeared to be lower in FHD+, compared to FHD-, children but did not reach significance ( $p>0.05)$. There were no group differences in age ( $p=0.241)$ and no group differences in verbal or non-verbal IQ (Verbal: $p=0.489 /$ Non-verbal: $p=0.452)$. Furthermore, there was no significant difference $(p>0.05)$ in socioeconomic status (SES; e.g. parental education and total family income over the last 12 month) or home literacy environment (HLE; e.g. age of child when first read to, total number of adult or children books at home) between groups (Table 1, SI1 and SI2).

\section{VBM}

Voxel-based morphometry (VBM5) revealed significantly reduced gray matter volume indices (GMVIs) for FHD+ compared to FHD- children in left occipitotemporal area (LOT: $x=-43, y=-66, z=4$ ), left and right temporoparietal regions (LTP: $x=-57, y=-34, z=26$; / RTP: $x=46, y=-29, z=24$ ), left fusiform (LFG; $x=-45, y=-60, z=-14)$ and right lingual gyrus (RLG; $x=23, y=-87, z=-11$ ) at $p<0.001$ (corrected for non-stationarity; $p<0.01$ ) (see Fig. 1a-c and Table 2). The reported differences are displayed on our customized pediatric brain template and MNI coordinates also reflect our pediatric brain template generated with Template-O-Matic (Wilke et al., 2008), which optimally reflects our age range (mean: 5 years and 9 months) and hence the average brain development stage of our participant group. There were no significant differences in gray matter volume indices for the inverse contrast (FHD+ $>$ FHD-; at $p<0.001)$ and no differences in total gray matter $(p=0.760)$ or total intracranial volume $(p=0.772)$ between FHD+ compared to FHD- children.

\section{Region of interest (ROI) analyses}

Correlation analyses for standardized behavioral measures of phonological processing and RAN with GMVIs revealed significant positive Pearson correlations for the left temporoparietal and left occipitotemporal ROI with RAN (LTP: $r=0.26, p=0.023 / \mathrm{LOT} / \mathrm{LFG}$ $r=0.32, p=0.009$; Fig. 1d-e). No significant correlations were found for the two ROIs with phonological processing. Because of the previously reported strong relationship between left occipitotemporal brain region and phonological processing in functional and structural studies (e.g. Hoeft et al., 2007b; Temple, 2002; Kronbichler et al., 2008; Pernet et al., 2009) we additionally extracted GMVIs from a non-independent ROI within our left occipitotemporal region (LOT) which exhibited significantly less gray matter volume in FHD+, compared to FHD-, children. GMVIs in LOT significantly correlated with phonological processing $(r=0.25, p=0.024)$ and $\operatorname{RAN}(r=0.47, p=0.037)$.

\section{Discussion}

We observed reduced gray matter volume indices in a small group of pre-reading children with a family-history of developmental dyslexia, compared to children without a familyhistory, in brain areas known to be involved during reading and reading development (McCandliss and Noble, 2003; Schlaggar and McCandliss, 2007). If these structural brain differences are replicated in future studies with larger samples, reduced gray matter volume may provide a biomarker useful for education. These regions include the left occipitotemporal area, bilateral temporoparietal regions, left fusiform gyrus and right lingual gyrus. Furthermore, GMVIs within left hemispheric temporoparietal and occipitotemporal 
ROIs (created based on a meta-analysis on reading networks, Jobard et al., 2003) correlated with RAN skills. There were no significant differences in early literacy experience or socioeconomic background between children with compared to children without a familyhistory of developmental dyslexia, and therefore these variables do not account for the present findings.

The observed structural brain differences in pre-readers at risk for developmental dyslexia, compared to control children, correspond to brain regions that have been shown to differ (structurally and functionally) between individuals with developmental dyslexia and typical readers. In particular, our results are consistent with VBM studies that demonstrated gray matter differences in left occipitotemporal and bilateral temporoparietal areas (Brambati et al., 2004; Brown et al., 2001; Eckert et al., 2005; Hoeft et al., 2007a; Kronbichler et al., 2008; Pernet et al., 2009; Silani et al., 2005), fusiform (Kronbichler et al., 2008) and lingual gyrus (Eckert et al., 2005) in children and adults with a diagnosis of developmental dyslexia compared to typical-reading controls. Furthermore, our findings are supported by VBM and DTI studies demonstrating reduced white matter connectivity and white matter indices in left-hemispheric occipitotemporal regions in adults (Klingberg et al., 2000; Steinbrink et al., 2008) and children (Deutsch et al., 2005; Niogi and McCandliss, 2006; Rimrodt et al., 2009) with developmental dyslexia.

Previous research using fMRI shed light on the role of brain structures that significantly differ in individuals with developmental dyslexia when compared to typical readers. These studies indicate that the left occipitotemporal area is activated during tasks of phonological processing (Temple, 2002) and tasks requiring the visual analysis of letters and words (Cohen et al., 2003; McCandliss et al., 2003; Vinckier et al., 2007). The left fusiform gyrus is involved in rapid recognition of visual words (McCandliss et al., 2003; Vinckier et al., 2007) and gains particular importance during the later stages of reading development within the typical reading brain (McCandliss et al., 2003; Turkeltaub et al., 2003). The temporoparietal area is known to be important for the integration of letters and speech sounds (Van Atteveldt et al., 2004, 2007), a key skill for reading in starting readers. Furthermore, research has shown that individuals with developmental dyslexia display deficits in letter sound integration within the temporal-parietal network (Blau et al., 2009; Blau et al., 2010).

In the current study in a small group of pre-reading children, GMVIs extracted from left hemispheric parietotemporal and occipitotemporal brain regions significantly correlated with rapid automatized naming. Rapid automatized naming is commonly impaired in children and adults with dyslexia and was reported to be one of the main precursors of later reading ability in children (De Jong and Van der Leij, 1999; Kirby et al., 2003; Kobayashi et al., 2005; Wolf, 1986; Wolf et al., 1986). Furthermore, previous research reported significant correlations between gray matter volume in a left occipitotemporal region and digit naming (Kronbichler et al., 2008). Previous research has suggested that RAN reflects the automatization or efficiency of matching visual/orthographic units to their phonological counterparts (e.g.; Vaessen et al., 2009; Vaessen and Blomert, 2010) or the efficient retrieval of phonological codes (e.g. Wagner and Torgesen, 1987). This is in line with our finding which shows a correlation between brain regions previously reported to be involved in phonological processing and RAN. However, RAN significantly differentiated our children with and without a family-risk of developmental dyslexia behaviorally before reading onset. Here, the observed anatomical differences may therefore reflect either a family-history or behavioral risk for developmental dyslexia. Further studies need to determine whether prereading children without a family history of dyslexia but a strong behavioral risk for dyslexia (e.g.; as determined by psychometric testing) also display the here observed anatomical alterations. 
Several studies have shown a reduction of gray and white matter in children and adults with DD which correlate with phonological processing (e.g. Kronbichler et al., 2008; Pernet et al., 2009) and correlations between functional differences in occipitotemporal and parietotemporal regions and phonological skills have also been reported (Hoeft et al., 2007b; Temple, 2002; Specht et al., 2009). In our present study, we only observed a significant correlation between gray matter volume indices in the left occipitotemporal area (LOT) and phonological processing in a ROI which was defined by our observed anatomical differences but not when using independent ROIs defined by coordinates from previous publications which reported a similar correlation or meta-analysis. Therefore, the results of this analysis need to be interpreted with caution (see discussion by Poldrack and Mumford, 2009; Vul et al., 2009). Although this lack of a relationship between phonological skills and GMVI in left hemispheric regions in our sample may suggest that this relationship develops after reading onset, or that RAN has a higher specificity at this age, there may be a methodological explanation for the missing correlation. In the present study, a pediatric template was utilized and previously reported results were reported for adult templates. Although independent ROIs can be normalized to the pediatric template (as performed here), the areas within occipitotemporal and parietotemporal regions that exhibited a difference in GMVIs between the two groups is relatively small and therefore ROIs defined based on coordinates from previous papers (with adult templates) were most likely not targeting the appropriate areas in our age group of pre-readers.

In contrast to VBM studies in individuals with developmental dyslexia, we did not observe structural brain alterations in left inferior frontal brain regions (Brown et al., 2001; Eckert et al., 2003) or the cerebellum (Brambati et al., 2004; Brown et al., 2001). However, we examined structural brain alterations in pre-readers at risk for dyslexia as opposed to individuals with diagnosed developmental dyslexia or reading difficulties. It has been suggested that the alterations in frontal brain regions observed in children and adults with developmental dyslexia develop after the age of reading onset, mirroring the influence of experience and reading education (Hoeft et al., 2007a). Structural (Brambati et al., 2004; Brown et al., 2001) and functional MRI studies (Fulbright et al., 1999; Vlachos et al., 2007) have shown an involvement of the cerebellum during reading processes, such as word identification, phonological assembly and semantic processing. Our results complement these studies and suggest that structural differences in the left occipitotemporal area, bilateral temporoparietal regions, left fusiform gyrus and right lingual gyrus in children with a family-history of dyslexia prior to reading-onset are likely a pre-existing biological deficit. Further alterations, such as those seen in frontal regions and the cerebellum, might reflect experience-dependent changes that typically coincide with the process of learning to read.

\section{A comprehensive model of dyslexia}

Progress toward understanding developmental dyslexia has come from multiple levels. It has been suggested that developmental dyslexia may be a developmental disorder of genetic origin with a neurobiological basis (Galaburda et al., 2006; Silani et al., 2005). In line with the most recent neurobiological and genetic findings, our results seem to support a comprehensive model of developmental dyslexia which incorporates variant function in genes involved in brain development, structural and functional brain alterations and prereading skills (Galaburda et al., 2006). To date, several genes (e.g.; ROBO1, DCDC2, DYX1C1, KIAA0319) have been reported to be candidates for dyslexia susceptibility and it has been suggested that the majority of these genes plays a role in brain development (Galaburda et al., 2006; Hannula-Jouppi et al., 2005; Meng et al., 2005; Paracchini et al., 2006). Since the structural alterations revealed in the present study predate the onset of formal reading instruction and as there are no significant group differences in socioeconomic status or home literacy environment, it can be hypothesized that genetic 
factors critical for brain development may be responsible for the observed cortical alterations. More specifically, the cortical alterations in pre-reading children at risk for developmental dyslexia may originate from abnormal migration and/or maturation of neurons during early development which may lead to altered functional brain circuits and result in impaired pre-reading and reading skills (Galaburda et al., 2006). Interestingly, we observed reduced and not increased gray matter indices in children with compared to without a family history of developmental dyslexia which speaks against effects of synaptic pruning at this young age where one would expect increased abnormality being associated with increased gray matter in certain cortical areas. Our reduced gray matter findings support previous hypotheses that reading disabilities, such as developmental dyslexia, are characterized by neural migration failure (e.g.; Chang et al., 2005, 2007; Galaburda et al., 2006) and are further in line with the finding that four of the main candidate susceptibility genes (DYX1C1, KIAA0319, DCDC2, ROBO1) are linked to neuronal migration and other developmental processes (Galaburda et al., 2006). Furthermore, deviations in the migration of neurons from proliferative zones towards the cortex have also been found in post-mortem examination of individuals with developmental dyslexia (Galaburda et al., 1985) and reading and processing speed deficits have been reported for patients with neuronal migration disorder of periventricular nodular heterotopia (Chang et al., 2005).

Nevertheless, no specific cognitive processes are known to be directly influenced by the reported susceptibility genes (Schumacher et al., 2007). It remains unclear whether any of the reported genes are associated with specific cognitive phenotype dimensions or whether there are any interactions among the genes. Gene-environment interactions should not be underestimated. A series of major environmental risks are known to play a crucial role in the manifestation of developmental dyslexia, such as socio-economic status, educational opportunities and home literacy environment. Although the risk for dyslexia is greater among first degree relatives of individuals with dyslexia, one needs to keep in mind that only approximately $40 \%$ of all children with a family history of dyslexia will later develop reading disabilities themselves (Pennington and Smith, 1988). This suggests that gene-gene interactions, early compensation strategies and environmental factors not shared by siblings as well as educational (e.g.; teaching style), psychological factor and their interaction with genetics may play a larger role in the manifestation of developmental dyslexia than anticipated.

Follow-up studies in young infants with and without a family history of developmental dyslexia may help to explain the underlying developmental mechanism for the here observed reduced gray matter indices in 5 year olds. Further examinations of models incorporating genetic vulnerability, structural and functional neuroimaging measures, environmental factors and behavioral skills will be crucial for a complete understanding of the etiology of developmental dyslexia.

\section{Conclusion}

Structural brain alterations have previously been observed in children and adults with developmental dyslexia. Developmental dyslexia can only be diagnosed after formal reading instruction begins. However, our findings in a small group of pre-reading children demonstrate that previously described gray matter alterations in children and adults with developmental dyslexia in parietotemporal, occipitotemporal brain areas and left fusiform and right lingual gyrus are already observable in pre-readers with a family-history of developmental dyslexia and correlate with pre-reading skills. These findings cannot be explained by differences in socioeconomic background or early literacy experiences. This discovery suggests that structural alterations in developmental dyslexia may be present at birth or may develop in early childhood. Future research using larger sample sizes and 
longitudinal designs are needed to determine whether these structural alterations may be utilized for the identification of children at risk for developmental dyslexia in infancy and/or early childhood.

\section{Supplementary Material}

Refer to Web version on PubMed Central for supplementary material.

\section{Acknowledgments}

This research was funded by the Charles H. Hood Foundation, a Children's Hospital Boston pilot grant, the Swiss National Foundation and the Janggen-Pöhn Stiftung (N.M.R.).

\section{Abbreviations}

$\begin{array}{ll}\text { FHD+ } & \text { children with a family-history of dyslexia } \\ \text { FHD- } & \text { children without a family-history of dyslexia } \\ \text { VBM } & \text { voxel-based morphometry } \\ \text { DTI } & \text { diffusion tensor imaging } \\ \text { RAN } & \text { rapid automatized naming } \\ \text { WRMT } & \text { Woodcock Reading Mastery Test } \\ \text { CELF } & \text { Clinical Evaluation of Language Fundamentals } \\ \text { CTOPP } & \text { Comprehensive Test of Phonological Processing } \\ \text { SES } & \text { socioeconomic status } \\ \text { HLE } & \text { home literacy environment } \\ \text { GMVI } & \text { gray matter volume indices } \\ \text { ROI } & \text { region of interest } \\ \text { LOT } & \text { left occipitotemporal area } \\ \text { LTP } & \text { left temporoparietal region } \\ \text { RTP } & \text { right temporoparietal region } \\ \text { LFG } & \text { left fusiform gyrus } \\ \text { RLG } & \text { right lingual gyrus }\end{array}$

\section{References}

Ashburner J, Friston KJ. Unified segmentation. Neuroimage. 2005; 26:839-851. [PubMed: 15955494]

Beitchman JH, Nair R, Clegg M, Ferguson B, Patel PG. Prevalence of psychiatric disorders in children with speech and language disorders. J. Am. Acad. Child Psychiatry. 1986; 25:528-535. [PubMed: 3489024]

Benjamini Y, Hochberg Y. Controlling the false discovery rate: a practical and powerful approach to multiple testing. J. R. Stat. Soc., Ser. B. 1995; 57(1):289-300. Methodological.

Blau V, Van Atteveldt N, Ekkebus M, Goebel R, Blomert L. Reduced neural integration of letters and speech sounds links phonological and reading deficits in adult dyslexia. Curr. Biol. 2009; 19(6): 503-508. [PubMed: 19285401]

Blau V, Reithler J, Van Atteveldt N, Seitz J, Gerretsen P, Goebel R, Blomert L. Deviant processing of letters and speech sounds as proximate cause of reading failure: a functional magnetic resonance imaging study of dyslexic children. Brain. 2010; 133:868-879. [PubMed: 20061325] 
Brambati SM, Termine C, Ruffino M, Stella G, Fazio F, Cappa SF, Perani D. Regional reductions of gray matter volume in familial dyslexia. Neurology. 2004; 63:742-745. [PubMed: 15326259]

Brown, AL.; Palincsar, AS.; Purcell, L. The school achievement of minority children: New perspectives. Lawrence Erlbaum; Hilsdale, NJ: 1986. Poor readers: teach, don't label.; p. 105-143.

Brown WE, Eliez S, Menon V, Rumsey JM, White CD, Reiss AL. Preliminary evidence of widespread morphological variations of the brain in dyslexia. Neurology. 2001; 56:781-783. [PubMed: 11274316]

Chang BS, Ly J, Appignani B, Bodell A, Apse KA, Ravenscroft RS, Sheen VL, Doherty MJ, Hackney DB, O'Connor M, Galaburda AM, Walsh CA. Reading impairment in the neuronal migration disorder of periventricular nodular heterotopias. Neurology. 2005; 64:799-803. [PubMed: 15753412]

Chang BS, Katzir T, Liu T, Corriveau K, Barzillai M, Apse KA, Bodell A, Hackney D, Alsop D, Wong S, Walsh CA. A structural basis for reading fluency: white matter defects in a genetic brain malformation. Neurology. 2007; 69:2146-2154. [PubMed: 18056578]

Cohen L, Martinaud O, Lemer C, Lehericy S, Samson Y, Obadia M, Slachevsky A, Dehaene S. Visual word recognition in the left and right hemispheres: anatomical and functional correlates of peripheral alexias. Cereb. Cortex. 2003; 13:1313-1333. [PubMed: 14615297]

Cunningham AE, Stanovich KE. Tracking the unique effects of print exposure in children: association with vocabulary, general knowledge, and spelling. J. Educ. Psychol. 1991; 83:264-274.

De Jong PF, Van der Leij A. Specific contributions of phonological abilities to early reading acquisition: results from a Dutch latent variable longitudinal study. J. Educ. Psychol. 1999; 91:450-476.

Denney, MK.; English, JP.; Gerber, M.; Leafstedt, J.; Rutz, M. Family and home literacy practices: mediating factors for preliterate English learners at risk.. Paper presented at the annual meeting of the American Educational Research Associations; Seattle, WA. 2001.

Denton, K.; Germino-Hausken, E.; West, J. U.S. Department of Education. National Center for Education Statistics; Washington, DC: 2000. America's Kindergartners, NCES 2000-20070

Deutsch GK, Dougherty RF, Bammer R, Siok WT, Gabrieli JD, Wandell B. Children's reading performance is correlated with white matter structure measured by diffusion tensor imaging. Cortex. 2005; 41:354-363. [PubMed: 15871600]

Eckert MA, Leonard CM, Richards TL, Aylward EH, Thomson J, Berninger VW. Anatomical correlates of dyslexia: frontal and cerebellar findings. Brain. 2003; 126:482-494. [PubMed: 12538414]

Eckert MA, Leonard CM, Wilke M, Eckert M, Richards T, Richards A, Berninger V. Anatomical signatures of dyslexia in children: unique information from manual and voxel based morphometry brain measures. Cortex. 2005; 41:304-315. [PubMed: 15871596]

Fisher SE, Francks C. Genes, cognition and dyslexia: learning to read the genome. Trends Cogn. Sci. 2006; 10:250-257. [PubMed: 16675285]

Flax JF, Realpe-Bonilla T, Roesler C, Choudhury N, Benasich A. Using early standardized language measures to predict later language and early reading outcomes in children at high risk for language-learning impairments. J. Learn. Disabil. 2008; 42:61-75. [PubMed: 19011122]

Francis DJ, Shaywitz SE. Developmental lag versus deficit models of reading disability: a longitudinal, individual growth curves analysis. J. Educ. Psychol. 1996; 88:3-17.

Fulbright RK, Jenner AR, Mencl WE, Pugh KR, Shaywitz BA, Shaywitz SE, Frost SJ, Skudlarski P, Constable RT, Lacadie CM, Marchione KE, Gore JC. The cerebellum's role in reading: a functional MR imaging study. AJNR Am. J. Neuroradiol. 1999; 20:1925-1930. [PubMed: 10588120]

Gabrieli JD. Dyslexia: a new synergy between education and cognitive neuroscience. Science. 2009; 325:280-283. [PubMed: 19608907]

Galaburda AM, Sherman GF, Rosen GD, Aboitiz F, Geschwind N. Developmental dyslexia: four consecutive cases with cortical anomalies. Ann. Neurol. 1985; 18:222-233. [PubMed: 4037763]

Galaburda AM, LoTurco J, Ramus F, Fitch RH, Rosen GD. From genes to behavior in developmental dyslexia. Nat. Neurosci. 2006; 9:1213-1217. [PubMed: 17001339] 
Gallagher A, Frith U, Snowling MJ. Precursors of literacy delay among children at genetic risk of dyslexia. J. Child Psychol. Psychiatry. 2000; 41:203-213. [PubMed: 10750546]

Guttorm TK, Leppanen PH, Richardson U, Lyytinen H. Event-related potentials and consonant differentiation in newborns with familial risk for dyslexia. J. Learn. Disabil. 2001; 34:534-544. [PubMed: 15503568]

Guttorm TK, Leppanen PH, Tolvanen A, Lyytinen H. Event-related potentials in newborns with and without familial risk for dyslexia: principal component analysis reveals differences between the groups. J. Neural Transm. 2003; 110:1059-1074. [PubMed: 12938027]

Hannula-Jouppi K, Kaminen-Ahola N, Taipale M, Eklund R, Nopola-Hemmi J, Kaariainen H, Kere J. The axon guidance receptor gene ROBO1 is a candidate gene for developmental dyslexia. PLoS Genet. 2005; 1:e50. [PubMed: 16254601]

Hayasaka S, Phan KL, Liberzon I, Worsley KJ, Nichols TE. Nonstationary cluster-size inference with random field and permutation methods. Neuroimage. 2004; 22:676-687. [PubMed: 15193596]

Hoeft F, Meyler A, Hernandez A, Juel C, Taylor-Hill H, Martindale JL, McMillon G, Kolchugina G, Black JM, Faizi A, Deutsch GK, Siok WT, Reiss AL, Whitfield-Gabrieli S, Gabrieli JD. Functional and morphometric brain dissociation between dyslexia and reading ability. Proc. Natl Acad. Sci. USA. 2007a; 104:4234-4239. [PubMed: 17360506]

Hoeft F, Ueno T, Reiss AL, Meyler A, Whitfield-Gabrieli S, Glover GH, Keller TA, Kobayashi N, Mazaika P, Jo B, Just MA, Gabrieli JD. Prediction of children's reading skills using behavioral, functional, and structural neuroimaging measures. Behav. Neurosci. 2007b; 121:602-613. [PubMed: 17592952]

Hollingshead, A. de B. Four factor index of social status. Department of Sociology, Yale University; 1975.

Jobard G, Crivello F, Tzourio-Mazoyer N. Evaluation of the dual route theory of reading: a metanalysis of 35 neuroimaging studies. Neuroimage. 2003; 20(2):693-712. [PubMed: 14568445]

Katzir, T.; Lesaux, NK.; Kim, Y-S. Reading and Writing, An Interdisciplinary Journal. 2009. The role of reading self-concept and home literacy practices in fourth grade reading comprehension.. http:// www.springerlink.com.ezp-prod1.hul.harvard.edu/content/1176180535083720/fulltext.html

Kaufman, AS.; Kaufman, NL. KBIT-2: Kaufman Brief Intelligence Test. 2nd ed.. NCS Pearson, Inc; Minneapolis, MNP: 1997.

Kirby JR, Parrila RK, Pfeiffer SL. Naming speed and phonological awareness as predictors of reading development. J. Educ. Psychol. 2003; 95:453-464.

Klingberg T, Hedehus M, Temple E, Salz T, Gabrieli JD, Moseley ME, Poldrack RA. Microstructure of temporo-parietal white matter as a basis for reading ability: evidence from diffusion tensor magnetic resonance imaging. Neuron. 2000; 25:493-500. [PubMed: 10719902]

Kobayashi MS, Haynes CW, Macaruso P, Hook PE, Kato J. Effects of mora deletion, nonword repetition, rapid naming, and visual search performance on beginning reading in Japanese. Ann. Dyslexia. 2005; 55:105-128. [PubMed: 16107782]

Kronbichler M, Wimmer H, Staffen W, Hutzler F, Mair A, Ladurner G. Developmental dyslexia: gray matter abnormalities in the occipitotemporal cortex. Hum. Brain Mapp. 2008; 29:613-625. [PubMed: 17636558]

Leppanen PH, Richardson U, Pihko E, Eklund KM, Guttorm TK, Aro M, Lyytinen H. Brain responses to changes in speech sound durations differ between infants with and without familial risk for dyslexia. Dev. Neuropsychol. 2002; 22:407-422. [PubMed: 12405511]

Marder, C.e.a. A comparison of youth with disabilities and youth in general. Office of Special Education Programs, US Department of Education; Washington, DC: 1992. How well are youth with disabilities really doing?.

Maurer U, Bucher K, Brem S, Benz R, Kranz F, Schulz E, van der Mark S, Steinhausen H-C, Brandeis D. Neurophysiology in preschool improves behavioral prediction of reading ability throughout primary school. Biol. Psychiatry. 2009; 66:341-348. [PubMed: 19423082]

McCandliss BD, Noble KG. The development of reading impairment: a cognitive neuroscience model. Ment. Retard. Dev. Disabil. Res. Rev. 2003; 9:196-204. [PubMed: 12953299]

McCandliss BD, Cohen L, Dehaene S. The visual word form area: expertise for reading in the fusiform gyrus. Trends Cogn. Sci. 2003; 7:293-299. [PubMed: 12860187] 
Meng H, Smith SD, Hager K, Held M, Liu J, Olson RK, Pennington BF, DeFries JC, Gelernter J, O'Reilly-Pol T, Somlo S, Skudlarski P, Shaywitz SE, Shaywitz BA, Marchione K, Wang Y, Paramasivam M, LoTurco JJ, Page GP, Gruen JR. DCDC2 is associated with reading disability and modulates neuronal development in the brain. Proc. Natl Acad. Sci. USA. 2005; 102:1705317058. [PubMed: 16278297]

Niogi SN, McCandliss BD. Left lateralized white matter microstructure accounts for individual differences in reading ability and disability. Neuropsychologia. 2006; 44:2178-2188. [PubMed: 16524602]

Oka, E.; Paris, S. Patterns of motivation and reading skills in underachieving children.. In: Ceci, S., editor. Handbook of Cognitive, Social, and Neuropsychological Aspects of Learning Disabilities. Vol. 2. Erlbaum; Hillsdale, NJ: 1986. p. 220-237.

Paracchini S, Thomas A, Castro S, Lai C, Paramasivam M, Wang Y, Keating BJ, Taylor JM, Hacking DF, Scerri T, Francks C, Richardson AJ, Wade-Martins R, Stein JF, Knight JC, Copp AJ, Loturco J, Monaco AP. The chromosome 6p22 haplotype associated with dyslexia reduces the expression of KIAA0319, a novel gene involved in neuronal migration. Hum. Mol. Genet. 2006; 15:1659_ 1666. [PubMed: 16600991]

Pennington BF, Lefly DL. Early reading development in children at family risk for dyslexia. Child Dev. 2001; 72:816-833. [PubMed: 11405584]

Pennington BF, Smith SD. Genetic influences on learning disabilities: an update. J. Consult. Clin. Psychol. 1988; 56(6):817-823. [PubMed: 3060499]

Pernet C, Andersson J, Paulesu E, Demonet JF. When all hypotheses are right: a multifocal account of dyslexia. Hum. Brain Mapp. 2009; 7:2278-2292. [PubMed: 19235876]

Pihko E, Leppanen PH, Eklund KM, Cheour M, Guttorm TK, Lyytinen H. Cortical responses of infants with and without a genetic risk for dyslexia: I. Age effects. NeuroReport. 1999; 10:901905. [PubMed: 10321457]

Poldrack RA, Mumford JA. Independence in ROI analysis: where is the voodoo? Soc. Cogn. Affect. Neurosci. 2009; 4(2):208-213. [PubMed: 19470529]

Puolakanaho A, Ahonen T, Aro M, Eklund K, Leppanen PH, Poikkeus AM, Tolvanen A, Torppa M, Lyytinen H. Developmental links of very early phonological and language skills to second grade reading outcomes: strong to accuracy but only minor to fluency. J. Learn. Disabil. 2008; 41:353370. [PubMed: 18560022]

Quinn, MM.; Rutherford, RB., Jr.; Leone, PE. ERIC Digest. ERIC Clearing House on Disabilities and Gifted Education; Arlington, VA: 2001. Students with disabilities in correctional facilities.. ERIC Document Reproduction Service No. ED461958

Raschle NM, Lee M, Buechler R, Christodoulou JA, Chang M, Vakil M, Stering PL, Gaab N. Making MR imaging child's play_pediatric neuroimaging protocol, guidelines and procedure. J. Vis. Exp. 2009; 29 http://www.jove.com/index/details.stp? id=1309. doi:10.3791/1309.

Rimrodt SL, Peterson DJ, Denckla MB, Kaufmann WE, Cutting LE. White matter microstructural differences linked to left perisylvian language network in children with dyslexia. Cortex. 2009; 46(6):739-749. [PubMed: 19682675]

Scarborough HS. Very early language deficits in dyslexic children. Child Dev. 1990; 61:1728-1743. [PubMed: 2083495]

Schlaggar BL, McCandliss BD. Development of neural systems for reading. Annu. Rev. Neurosci. 2007; 30:475-503. [PubMed: 17600524]

Schumacher J, Hoffmann P, Schmäl C, Schulte-Körne G, Nöthen MM. Genetics of dyslexia: the evolving landscape. J. Med. Genet. 2007; 44(5):289-297. [PubMed: 17307837]

Semel, E.; Wiig, EH.; Secord, W. The Clinical Evaluation of Language Fundamentals-Revised. The Psychological Corporation; New York: 1986.

Silani G, Frith U, Demonet JF, Fazio F, Perani D, Price C, Frith CD, Paulesu E. Brain abnormalities underlying altered activation in dyslexia: a voxel based morphometry study. Brain. 2005; 128:2453-2461. [PubMed: 15975942]

Smith SD, Kimberling WJ, Pennington BF, Lubs HA. Specific reading disability: identification of an inherited form through linkage analysis. Science. 1983; 219:1345-1347. [PubMed: 6828864] 
Snowling MJ, Gallagher A, Frith U. Family risk of dyslexia is continuous: individual differences in the precursors of reading skill. Child Dev. 2003; 74:358-373. [PubMed: 12705560]

Specht K, Hugdahl K, Ofte S, Nygard M, Bjornerud A, Plante E, Helland T. Brain activation on prereading tasks reveals at-risk status for dyslexia in 6-year-old children. Scand. J. Psychol. 2009; 50(1):79-91. [PubMed: 18826418]

SPSS: SPSS Inc. SPSS Base 10.0 for Windows User's Guide. SPSS Inc; Chicago IL: 1999.

Steinbrink C, Vogt K, Kastrup A, Muller HP, Juengling FD, Kassubek J, Riecker A. The contribution of white and gray matter differences to developmental dyslexia: insights from DTI and VBM at 3.0 T. Neuropsychologia. 2008; 46:3170-3178. [PubMed: 18692514]

Temple E. Brain mechanisms in normal and dyslexic readers. Curr. Opin. Neurobiol. 2002; 12:178183. [PubMed: 12015234]

Torgesen, JK.; Buress, S. Consistency of reading-related phonological processes throughout early childhood: evidence from longitudinal-correlational and instructional studeis.. In: Metsala, J.; Ehri, L., editors. Word Recognition in Beginning Reading. Erlbaum; Hillsdale, NJ: 1998. p. 161-188.

Turkeltaub PE, Gareau L, Flowers DL, Zeffiro TA, Eden GF. Development of neural mechanisms for reading. Nat. Neurosci. 2003; 6:767-773. [PubMed: 12754516]

Vaessen A, Blomert L. Long-term cognitive dynamics of fluent reading development. J. Exp. Child Psychol. 2010; 105:213-231. [PubMed: 20042196]

Vaessen A, Gerretsen P, Blomert L. Naming problems do not reflect a second independent core deficit in dyslexia: double deficits explored. J. Exp. Child Psychol. 2009; 103:202-221. [PubMed: 19278686]

Van Atteveldt N, Formisano E, Goebel R, Blomert L. Integration of letters and speech sounds in the human brain. Neuron. 2004; 43(2):271-282. [PubMed: 15260962]

Van Atteveldt NM, Formisano E, Blomert L, Goebel R. The effect of temporal asynchrony on the multisensory integration of letters and speech sounds. Cereb. Cortex. 2007; 4:962-974. [PubMed: 16751298]

Vinckier F, Dehaene S, Jobert A, Dubus JP, Sigman M, Cohen L. Hierarchical coding of letter strings in the ventral stream: dissecting the inner organization of the visual word-form system. Neuron. 2007; 55:143-156. [PubMed: 17610823]

Vlachos F, Papathanasiou I, Andreou G. Cerebellum and reading. Folia Phoniatr. Logop. 2007; 59:177-183. [PubMed: 17627126]

Vul E, Harris C, Winkielman P, Pashler H. Puzzingly high correlation in fMRI studies of emotion, personality and social cognition. Perspect. Psychol. Sci. 2009; 4(3):274-290.

Wagner, M. The Transition Experiences of Young People with Disabilities. SRI International; Palo Alto, CA: 1993.

Wagner RK, Torgesen JK. The nature of phonological processing and its causal role in the acquisition of reading skills. Psychol. Bull. 1987; 101:192-212.

Wagner, RK.; Torgesen, JK.; Rashotte, CA. The Comprehensive Test of Phonological Processing. PRO-ED, Inc.; Austin, TX: 1999.

Wilke M, Holland SK, Altaye M, Gaser C. Template-O-Matic: a toolbox for creating customized pediatric templates. Neuroimage. 2008; 41:903-913. [PubMed: 18424084]

Wolf M. Rapid alternating stimulus naming in the developmental dyslexias. Brain Lang. 1986; 27:360-379. [PubMed: 3513900]

Wolf, M.; Denckla, MB. RAN/RAS: Rapid Automatized Naming and Rapid Alternating. PRO-ED, Inc.; Austin, TX: 2005.

Wolf M, Bally H, Morris R. Automaticity, retrieval processes, and reading: a longitudinal study in average and impaired readers. Child Dev. 1986; 57:988-1000. [PubMed: 3757613]

Woodcock, RW. Woodcock Reading Mastery Tests—Revised. NCS Pearson, Inc.; Minneapolis, MN: 1998.

World Health Organization. World Health Organization; Geneva: 1992. The ICD-10 Classification of Mental and Behavioral Disorders: Clinical Descriptions and Diagnostic Guidelines.. 



$\operatorname{LTP}(X=-57, Y=-34, Z=26)$

RTP ( $X=46, Y=-29, Z=24)$

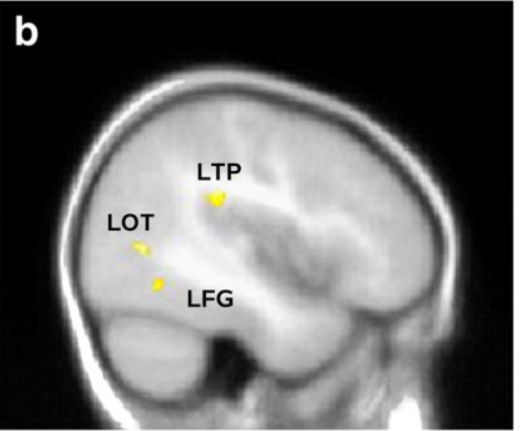

LTP ( $X=-57, Y=-34, Z=26)$

LOT ( $X=43, Y=-66, Z=4$ : indicated by arrow) $\operatorname{LFG}(X=-45, Y=-60, Z=-14)$

e d

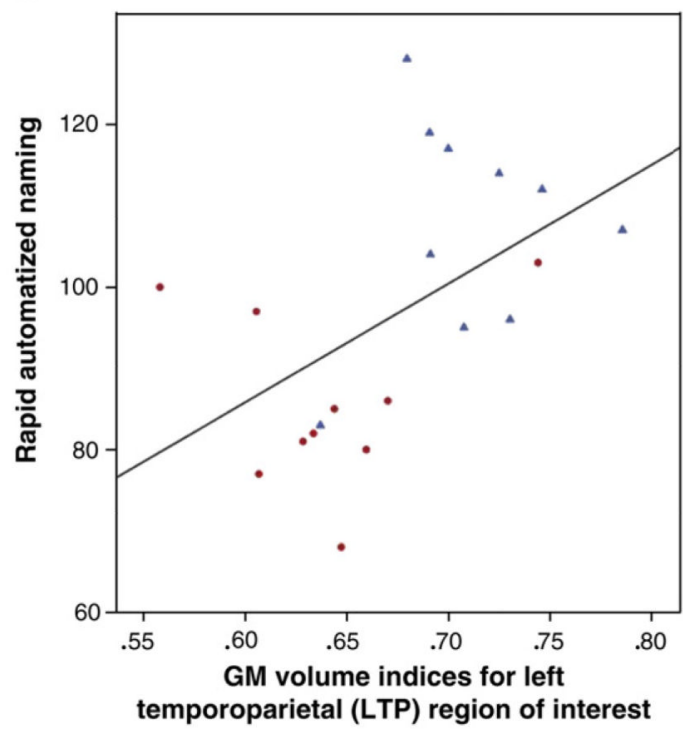

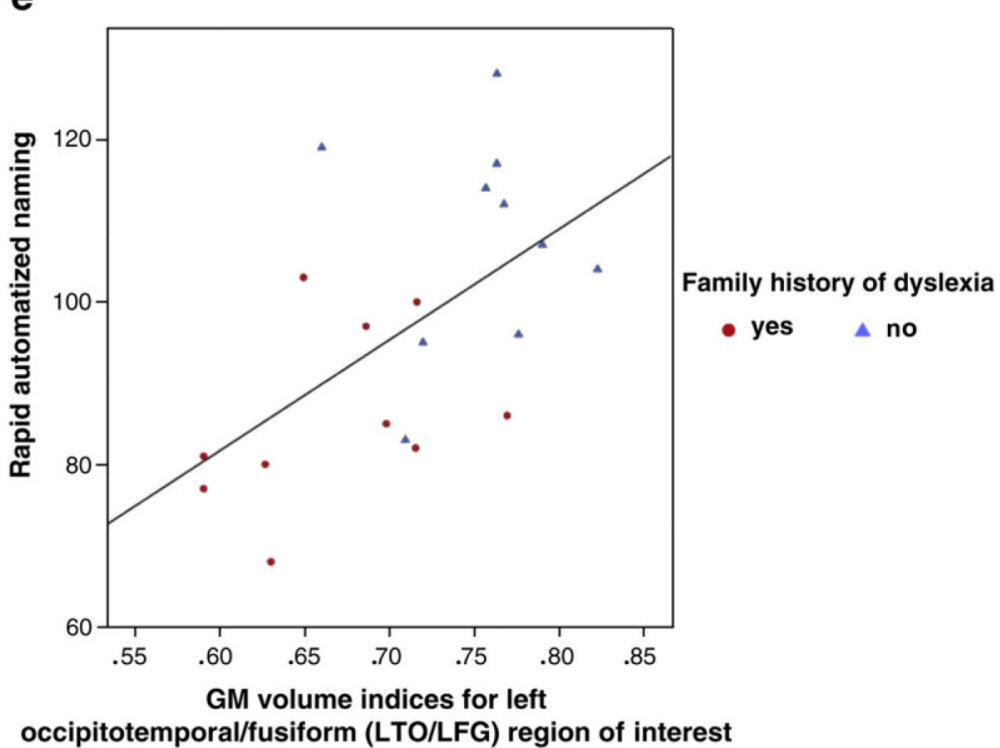

Fig. 1.

[a-c] Statistical parametric maps showing brain areas with significant decreased gray matter volume indices in pre-reading FHD+ compared to FHD- children ( $a=$ axial, $b=$ sagittal, $\mathrm{c}=$ coronal view). [d-e] Correlations between gray matter volume indices in the left parietotemporal (d) and left occipitotemporal (e) ROI and rapid automatized naming. 
Table 1

Subject demographics.

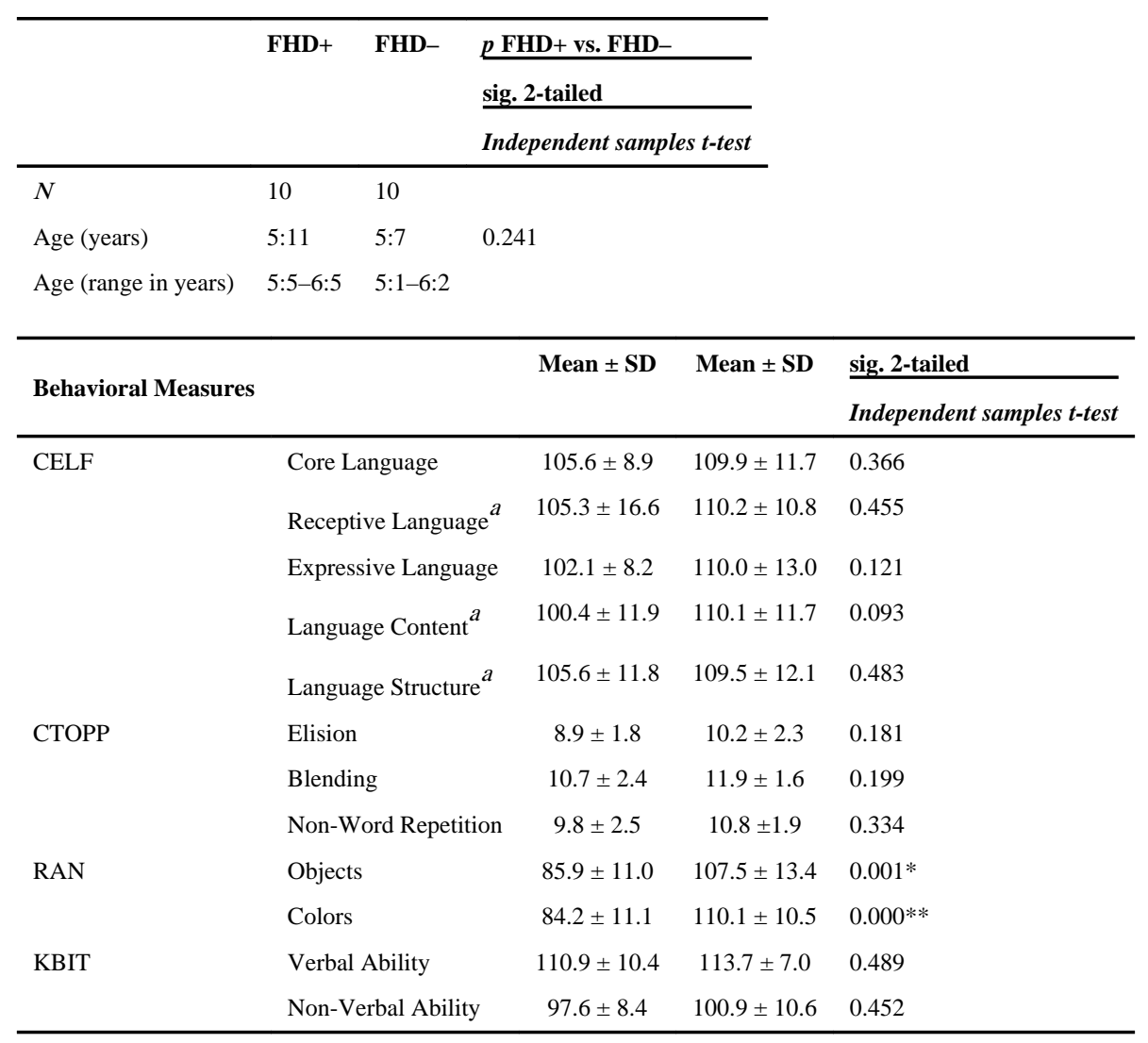

\begin{tabular}{lccl}
\hline Socioeconomic Status and Home Language Environment & Mean \pm SD & Mean \pm SD & sig. 2-tailed \\
\hline Parental Education $b$ & $6.2 \pm 0.5$ & $6.23 \pm 0.7$ & 0.749 \\
Age (in months) of child when first read to & $4.4 \pm 5.0$ & $9.8 \pm 19.0$ & 0.429 \\
Some one at home reads to the child [hours/week] & $2.7 \pm 1.4$ & $3.4 \pm 1.7$ & 0.336 \\
\hline
\end{tabular}

Mean Rank Mean Rank sig. 2-tailed

Kruskal-Wallis test

\begin{tabular}{llll}
\hline Income (total family income for last 12 months) & 8.83 & 9.19 & 0.865 \\
Total number of parents/adult books at home ${ }^{d}$ & 9.72 & 9.28 & 0.844 \\
Total number of children's books at home $^{d}$ & 8.50 & 10.50 & 0.146 \\
\hline
\end{tabular}

Measures (standard scores are reported).

two-tailed $t$-test; all other $t$-tests non-significant at threshold of $P=.05$.

* $P<.01$

*** $P<.001$

${ }^{a} 10$ FHD+/9 FHD- (One child did not finish all testing). 
$b_{\text {Parental Education scores are calculated according to the 7-point Hollingshead Index Educational Factor Scale, summed for husband and wife and }}$ divided by two (Hollingshead, 1975).

$c_{\text {Scale where } 1=50,000-74,999 \$, 2=75,000-99,999 \$, 3=100,000+\$ .}$

${ }^{d}$ Scale where $1=0-50$ books, $2=50-100$ books, $3=100+$ books. 
